\title{
MULHERES E A VIOLÊNCIA DE GÊNERO NO CONTEXTO SOCIOCULTURAL E LABORAL: REFERÊNCIA À REALIDADE DE RORAIMA
}

\author{
WOMEN AND GENDER VIOLENCE IN THE SOCIOCULTURAL AND LABOR CONTEXT: \\ REFERENCE TO THE REALITY OF RORAIMA
}

\author{
Douglas Verbicaro Soares \\ Universidade Federal de Roraima, Boa Vista, RR, Brasil. E-mail: douglas_verbicaro@yahoo.com.br \\ http://orcid.org/0000-0002-9242-9124 \\ Alessandra Moura Pedrosa Santos \\ Universidade Federal de Roraima, Boa Vista, RR, Brasil. E-mail: alessandramoura88@hotmail.com
}

\author{
Gabrielle Keller Sanches Pereira
}

Faculdade Faci - Wyden, Belém, PA, Brasil. E-mail: gabrielleksp@gmail.com

\section{Danielly da Silva Oliveira}

Universidade Federal de Roraima, Boa Vista, RR, Brasil. E-mail: oliveiradanielly28@gmail.com

DOI: https://doi.org/10.46550/amormundi.v2i1.16

Recebido em: 08.10.2020

Aceito em: 26.11.2021

\begin{abstract}
Resumo: $\mathrm{O}$ estudo tem por objetivo visibilizar a realidade das mulheres no âmbito laboral, social e coletivo, enfocando a questão da discriminação de gênero, influenciada por fatores histórico-culturais, políticos e religiosos transmitidos através dos séculos, por um modelo patriarcal de submissão feminina. A investigação abordará o tema da mulher destacando o fator humano, ou seja, as mulheres como agentes capazes de realizar qualquer tipo de atividade, náo importando os róis de gênero e modelos de masculinidades ou feminidades. Nesse aspecto, considerando as mulheres como seres aptos a realizar, também, atividades tipicamente masculinizadas em um ideal de forte tradição conservadora de discriminação. Foi realizada investigação bibliográfica e documental como procedimento metodológico, utilizando-se a abordagem qualitativa e o método dedutivo. A pesquisa conta com uma investigação bibliográfica multidisciplinar, como a história, as ciências jurídicas, a biologia e etc. A presente pesquisa conclui pela existência de discriminaçôes para as mulheres no Brasil, em especial no Estado de Roraima.
\end{abstract}

Palavras-chave: Discriminação; Igualdade; Inclusão Social.

Abstract: The study aims to visualize the reality of women in the labor, social and collective spheres, focusing on the issue of gender discrimination, influenced by historical-cultural, political and religious factors transmitted through the centuries, by a patriarchal model of female submission. The investigation will address the 
theme of women highlighting the human factor, that is, women as agents capable of performing any type of activity, regardless of gender and models of masculinities or femininities. In this respect, considering women as beings able to perform, also, typically masculinized activities in an ideal of strong conservative tradition of discrimination. A bibliographic and documentary investigation was carried out as a methodological procedure, using the qualitative approach and the deductive method. The research has a multidisciplinary bibliographic investigation, such as history, legal sciences, biology and etc. This research concludes by the existence of discrimination for women in Brazil, especially in the State of Roraima.

Keywords: Discrimination; Equality; Social Inclusion.

\section{Introdução}

presente estudo trabalhará a questão histórica como fonte de revelação de práticas de privaçóes e violências mais antigas, que continuam estigmatizando as mulheres. Para o desenvolvimento do trabalho, realizou-se uma pesquisa multidisciplinar, com método dedutivo, com destaque às ciências sociais aplicadas, em busca de explicaçóes acerca do tema.

$\mathrm{O}$ artigo foi estruturado em sete (sete) seçôes, elencando certos resquícios históricos de discriminação e busca pelos direitos de acesso igualitário às mulheres, desde experiências entre geraçóes, culminando com análises da conjuntura sociocultural brasileira, em destaque a realidade do Estado de Roraima. Assim, foram feitas certas indagaçôes, como por exemplo: Existe discriminação histórica para as mulheres no Brasil? Como a história plasmou o trabalho feminino? Existem instrumentos de proteção às mulheres para o combate da discriminação? Qual a previsão do Ordenamento Jurídico Brasileiro para a proteção das mulheres?

Mais adiante, se tomará a realidade existente para as mulheres no Estado de Roraima, transmitindo a urgência de análise do tema diante da presença de altos índices de violência de gênero e de estatísticas de crimes, bem como pela especificidade indígena e migrante particular no Estado. Serão mencionadas, também, medidas protetivas criadas nos âmbitos público e privado, visando amparar a mulher roraimense vítima de agressão e discriminação.

Para o trabalho foi pensada uma pesquisa multidisciplinar, dando destaque às ciências sociais (direito) em busca de explicaçóes acerca do tema.

\section{A discriminaçáo para o ser: mulher}

É válido destacar que nos séculos passados a participação feminina na sociedade brasileira passou de uma total postura de submissão desde sua infância até a vida adulta, quando passavam dos domínios de um pai para a figura de um esposo, sendo ensinadas a aceitar uma vida de cuidadora no âmbito privado, cuidadora da família (de um marido e dos filhos), onde lhes era típica a atribuição de ama de casa (VIEIRA, p. 28-9), preocupada com os cuidados da harmonia familiar do lar e nos cuidados diários com os filhos. Seus direitos se limitavam à figura de um homem, primeiro de um pai, irmão ou marido (VERBICARO SOARES, 2012, p. 13). Portanto, as mulheres eram silenciadas desde o nascimento por padróes sócio-comportamentais que definiam a maneira de ser e de se comportar em sociedade, mas que restringia o valor de suas vozes, de seus gêneros, sexualidade e construção da feminilidade (CARDOSO; ZIMMERMANN, 2020, p. 144). 
Nesse ambiente de impossibilidades, a conjuntura de realizar qualquer tipo de atividade laboral fora do contexto do lar, no espaço doméstico e de cuidados com a família representava apenas sonhos. Desse modo, existia um trato de inferioridade atribuído a essas mulheres (VERBICARO SOARES, 2019, p. 86), como se fossem personagens de uma segunda categoria, de menor importância social quando comparada a um homem (VERBICARO SOARES, 2012, p. 20). Seu desprestígio estava fundamentado na razão do sexo, do gênero e nos róis (VERBICARO SOARES et al., 2020, p. 43) estabelecidos historicamente na sociedade brasileira.

Foi durante a eclosão da Segunda Guerra Mundial que perpetuou uma mudança no modo de pensar e agir de diversas sociedades pelo mundo homem (VERBICARO SOARES, 2012, p. 20), implementando uma diferente forma de atuar das mulheres. Com esse contexto incluiu às mulheres em um ambiente distinto de trabalho fora dos lares familiares (BUSTOS, 2006, p. 1-2), onde as fábricas receberam mãos de obras femininas para dar continuidade às demandas bélicas da época.

Assim, as mulheres ocupam um espaço público antes permitido à apenas aos homens. Mas, da mesma forma que sua incorporação à atividade laboral, as condiçôes as que estão submetidas eram as piores imaginadas, uma vez que acabavam sendo desprestigiadas por serem mulheres e supostamente inferiores aos homens, supostamente sem autonomia, frustrada e castrada de sexualidade (VIEIRA, p. 28-9).

Com o passar dos tempos, as mulheres começam a se organizar reivindicando igualdades de condiçóes e respeito, almejando direitos antes a elas negados, por exemplo, o direito ao voto ou de acesso a um estudo superior (BUSTOS, 2006, p. 2). Essa conjuntura de reivindicação feminina permite o desenvolvimento de movimentos feministas em prol de melhores condiçóes de vida para as mulheres, abrindo espaço para o desenvolvimento pessoal e profissional das mulheres no mundo. Mudança que repercute no ideal de aceitação de uma submissão absoluta ao homem (PROBST, 2003).

É importante ressaltar que as mulheres ao longo da história da humanidade sofreram e ainda continuam sofrendo diferentes tipos de discriminaçóes por diversas questóes, seja por motivo religiosos de moral cristã ou judaica, ou pela incidência de preceitos biológicos na definição do sexo como inferior, ou também, na questão política que entendia as mulheres como pertencentes a um coletivo sem projeção pública não capacitadas, sem direitos, sem proventos econômicos (VERBICARO SOARES, 2019, p. 14-5). Cultural, pois integravam o espaço privado da submissão patriarcal e respeito a moldes rígidos comportamentais e hierarquizados (DIAS, 2016, p. 120), que reduziram à mulher à reprodução natural da espécie e limitadora no papel da sexualidade e diversidade sexual.

Com essas características que desprestigiam as mulheres, o fato de que a maioria delas continua a receber menores salários em relação aos companheiros homens (VERBICARO SOARES et tal., 2020, p. 93-4), mesmo assumindo as mesmas tarefas é um fator que comprova a existência de tetos de cristais que promovem e mantêm as desigualdades entre homens e mulheres.

Destarte, relatos cotidianos de assédios sexuais fazem parte da vida de muitas mulheres, obrigadas a lidar com a exposiçáo de suas sexualidades e na banalização da violência moral e física contra essas vítimas. Por essa razão, estudos que promovam a discussão social sobre temas de revelo como o gênero e políticas de igualdade são mecanismos indispensáveis para a criação 
de uma sociedade em harmonia com os preceitos fundamentais da igualdade, solidariedade, valorização da dignidade humana e na paz (VERBICARO SOARES, 2019, p. 154-5).

A luta da sociedade atual brasileira na promoção de ambientes mais harmônicos para homens e mulheres influencia diretamente no impacto das atividades humanas, em especial no âmbito de diversas atividades laborais. Dessa forma, tanto homens como mulheres podem e devem compartir do mesmo ideal de realização dessa prática, sem preconceitos ou discriminaçóes baseadas no sexo ou gênero.

Esse estudo está fundamentado no desenvolvimento das lutas das mulheres por sua inserção no mercado de trabalho e participação igualitária na sociedade brasileira, com influência de movimentos feministas que marcaram nos últimos dois séculos, a participação das mulheres na esfera pública com cidadãs aptas a desenvolver atividades profissionais, sem sofrer diminuição sócio moral por suas escolhas.

\section{Relatos históricos da participaçáo da mulher em atividades laborais no âmbito público}

De acordo com a história, o papel desempenhado pelas mulheres, em diversas sociedades, pode responder algumas questôes que fortalecem a formação de discriminaçóes sociais e masculinização de prática laboral. Sabe-se que em sociedades primitivas, se notavam diferenças significativas entre o trabalho de homens e mulheres. Para os primeiros, a utilização da força física propiciou a saída dos homens em busca de alimentos e no provento dos mesmos para o sustento familiar e do grupo. As mulheres, em contrapartida, ocuparam a funçáo de cuidadora, zelando pela preparação dos alimentos e atenção aos menores e anciãos do grupo. Nesse aspecto, caracterizando a questão das mulheres a uma inferioridade natural e de dependência aos homens (RODRIGUES; SELEM, 2006).

Para sociedades antigas do Egito, Grécia, Mesopotâmia, Roma, a participação laboral das mulheres foi centrada na atividade do cuidado de casa e dos filhos na família, sem a interferência feminina no núcleo público dessas sociedades. Na idade média, essa realidade foi mantida, preservando a submissão feminina ao homem. Na idade moderna, a atividade feminina centralizada no espaço doméstico (VERBICARO SOARES, 2012, p. 22), de menos importância social consolidou anos de exploração e desprestígio social da mulher.

Como se a condição de nascer mulher representasse um fado relacionado à sua condição natural e sexual, que justificava a dependência ao sexo do homem (REVISTA PARANAENSE DE DESENVOLVIMENTO, 2011, p. 65). Após anos de discriminaçóes e exclusão participativa das mulheres e proibiçôes ao acesso a direitos, é importante a alusão de que o ingresso das mulheres no espaço público foi um processo difícil, norteado na idade moderna e contemporânea de lutas de movimentos feministas para o reconhecimento de direitos e inclusão das mulheres em sociedade.

Inclusão reivindicada para modificar as situações de desigualdades nos mais variados setores: social, político, religioso, político e econômico. Com o passar dos tempos, as mulheres vão logrando mudanças que permitiram alteraçôes em modelos patriarcais e combate a situaçóes de desigualdades entre homens e mulheres (BUSTOS, 2006, p. 4). Entre essas mudanças, o modo de vida de uma época conservadora cede espaço para novas realidades de ocupaçóes femininas em busca da independência ao homem, em especial a econômica (GALVÁN, 2010, p. 
23). Paulatinamente, os anseios de trabalho fora do ambiente doméstico náo demoraram em ser iniciados, surgindo nesse aspecto a mulher como profissional laboral.

Atualmente, essa realidade de integração permite que mulheres, por exemplo, possam ser motoristas de veículos pesados ou pescadoras, assim como os homens possam exercer atividades profissionais como modistas ou cozinheiros. Apesar de todos os problemas enfrentados, as mulheres não deixaram de reivindicar melhores condiçóes de vida e acesso a direitos políticos e civis, buscando ocupar um espaço restrito aos homens. Hoje as mulheres lograram ocupar e a desempenhar diversas atividades laborais, afirmando a sua plena capacidade para trabalhar, não importando, portanto, o seu sexo.

\section{$4 \mathrm{O}$ movimento feminista e os instrumentos de proteçáo da mulher pelo mundo}

No decorrer da história sempre houve mulheres que se rebelaram contra as condiçóes que lhe eram postas como "corretas", mulheres que sempre lutaram pela garantia dos seus direitos, bem como por sua liberdade.

O movimento feminista surgiu com as diversas reivindicaçóes de mulheres pelo mundo todo e dentre os primeiros movimentos estão os textos "Uma defesa dos direitos da mulher" de Mary Wollstonecraft, 1792, e Declaração dos Direitos da Mulher e da Cidadã de Olympe de Gouges, 1791 (GALVÁN, 2010, p. 27), ambos os textos exigem a igualdade de direitos para as mulheres, pois estas eram bastante oprimidas pelos homens, e foram escritos no contexto da Revolução Francesa na temática da liberdade, igualdade e fraternidade entre todos os cidadãos, tentando obter uma sociedade que não fosse tão desigual (WOLLSTONECRAFT, 1977).

Ademais, a história de reivindicação das mulheres por acesso aos mesmos direitos que os homens, acompanharam um processo de mudanças no âmbito pessoal e profissional, que romperam padrôes convencionais baseados em valor socioculturais e históricos pela promoção de uma real igualdade de trato entre os gêneros (BUSTOS, 2006, p. 2). Esse processo de mudança alterou o que antes era característico das atividades das mulheres, ou seja: a submissão ao trabalho na esfera doméstica, dentro de casas, cuidando da família (filhos e marido). Geralmente essas atividades atribuíram às mulheres uma condição de inferioridade, inerente de um modelo patriarcal, machista que renegou a participação feminina em igualdade de condições.

Para frear os obstáculos que impediam a emancipação das mulheres e o acesso aos mesmos direitos que os homens, movimentos sociais proclamaram desigualdades nos moldes sociais, que desconstruíram a naturalidade dos gêneros e a influência de modelos estigmatizastes. Por esta razão, a busca pela igualdade de trato entre homens e mulheres, presente nas reivindicaçôes de movimentos feministas, passa pela criação de instrumentos legais de proteção de direitos. Seja no âmbito regional de um direito, previsto no ordenamento jurídico de um país, ou por meio de orientaçóes internacionais, que levam em conta preceitos compartidos universalmente que promovam a efetiva igualdade entre os gêneros.

Mudar essas realidades de desigualdades precisa de uma conscientização conjunta da sociedade brasileira, junto com o Estado e, também, com a participação internacional que possam permitir que as mulheres tenham efetiva participação em respeito nos diversos setores, na economia, na política, no direito, atuando em igualdades de condição com os homens, uma vez que os gêneros náo podem servir como limitação no desempenho de qualquer tipo de 
atividade, muito menos como justificativa para alijar as mulheres de se desenvolver plenamente em sociedade (VALLADARES, 2018, p. 66).

Assim, afrontar os desafios para a igualdade necessita tratar e reformular o conjunto socialpolítico do Estado de bem-estar no Brasil. Com essa conjuntura, Instrumentos de Proteção para as mulheres foram criados por diferentes países.

$\mathrm{Na}$ esfera internacional tratando de os temas de proteção dos Direitos Humanos e no reconhecimento dos 70 anos da Declaração Universal dos Direitos Humanos em 2018 (SENADO, 2018), o Governo do Brasil, visando proteger as mulheres vitimadas ao largo da história firma sua participação e se compromete a cumprir com as recomendaçôes internacionais para promover, proteger e incluir as mulheres na sociedade brasileira. Alguns dos documentos internacionais a ser utilizados:

Declaração e Plataforma de Ação da III Conferência Mundial sobre Direitos Humanos (Viena - Áustria, 1993); Essa Declaração visa promover os objetivos de igualdade, desenvolvimento e paz para todas as mulheres, em todo o mundo, de acordo com os interesses humanitários (GALVÁN, 2010, p. 128). Esse mecanismo ressalta que a violência justificada no gênero é incompatível com a dignidade e o valor do ser humano, sendo necessária a eliminada essa incompatibilidade, por meio de medidas legais, ou seja, através de açôes no âmbito nacional de um Estado ou pela cooperação internacional nas áreas de desenvolvimento, economia, social, educacional, saúde e etc.

Declaração e Plataforma de Ação da Conferência Internacional sobre População e Desenvolvimento do Cairo - Egito, 1994 (VERBICARO SOARES, 2012, p. 36). Representa uma importante modificação no âmbito social, uma vez que efetiva o ideal de direitos reprodutivos, e consequentemente, direcionando para a regulação de temas como fecundidade. A importância dessa Declaração se encontra no reconhecimento da eliminação de todas as formas de violência contra a mulher, assim como a reivindicaçáo pela igualdade entre os gêneros, do poder feminino, inclusive em questóes sobre controle sobre sexualidade e reprodução.

Convenção Interamericana para Prevenir, Punir e Erradicar a Violência contra a Mulher. Convenção de Belém do Pará - Brasil (1994); Ratificada pelo Brasil em 1995, a Convenção tem força interna no país segundo a Constituição Federal de 1988, maios especificamente no seu parágrafo $2^{\circ}$, do artigo $5^{\circ}$ (VERBICARO SOARES, 2012, p. 36). Representa o esforço do movimento feminista internacional para dar visibilidade à violência contra a mulher e exige o repudio a essas açóes discriminatórias pelos Estados membros da Organização dos Estados Americanos - OEA. É válido recordar que a Convenção declara que a violência contra as mulheres representa também uma violação aos Direitos Humanos.

Declaração e Plataforma de Ação da IV Conferência Mundial sobre a Mulher (Pequim - China, 1995); firmada pelo Governo brasileiro, essa Declaração evidencia as manifestaçôes internacionais de combate à violência, uma das principais causas impeditivas da igualdade, desenvolvimento e paz. Ademais de dificultar a promoção e o respeito aos Direitos Humanos e as liberdades fundamentais (VERBICARO SOARES, 2012, p. 36). Nesse sentido, a Declaraçáo implementou medidas recomendáveis para conseguir a prevenção, proteção e reparação das vítimas, incentivando a educação, a eliminação de práticas prejudiciais (ideais de superioridade e inferioridade entre os sexos), reabilitação dos agressores e etc. 
Convenção para a eliminação de todas as formas de discriminação contra a mulher CEDAW- Convention On Elimination of Discrimination Against Women (1979); que entrou em vigor no ano de 1981, sendo ratificada pelo Governo brasileiro em 1984 (VERBICARO SOARES, 2012, p. 37). Trata da obrigação do Estado ratificador em assegurar a igualdade entre homes e mulheres e de eliminar todos os tipos de discriminação contra a mulher. Essa Convençáo representa um dos primeiros mecanismos internacionais que defendia a efetividade dos direitos das mulheres e a igualdade entre os sexos.

Para Lalaguna e Salazar (2011), o texto da Convenção se destaca uma vez que foi a primeira vez que um instrumento internacional de Direitos Humanos especificou a definição da discriminação contra as mulheres. Outra questão destacável esteve na proposição de medidas de caráter jurídico que ajudam as mulheres, em especial, que estas medidas não fossem interpretadas como contrarias à igualdade entre todos os seres humanos, ou seja: que são empregadas e justificadas para modificar desigualdades historias existentes que foram favoráveis aos homens ao longo da história da humanidade.

Protocolo Facultativo à CEDAW (1999); ratificado pelo Brasil em 2001, obrigando o Estado brasileiro em cumprir suas normas e reconhecendo a competência do Comitê CEDAW para receber denúncias de não respeito às normas integradoras da Convenção para a Eliminação de todas as formas de discriminação contra a mulher (VERBICARO SOARES, 2012, p. 37 8). Foi por meio desse Protocolo que se permitiu a proteção das pessoas ou grupos de sofrer violaçôes a direitos e de viabilizar denúncias ao Comitê nos casos de desrespeito, possibilitando acesso das mulheres vítimas de violência à justiça internacional.

Declaração e Programa de Ação da III Conferência Mundial contra o Racismo, Discriminação Racial, Xenofobia e Intolerância de Durban - África do Sul, 2001 (VERBICARO SOARES, 2012, p. 38). Essa Declaração reafirmou os princípios de igualdade e não discriminação, reconhecidos na Declaraçáo Universal de Direitos Humanos e incentivos ao respeito a esses direitos, assim como das liberdades fundamentais para todos, sem distinção de qualquer tipo, seja por raça, cor, sexo, língua, opiniáo, origem social, nascimento e outros.

Recomendações e Convenções da Organização Internacional do Trabalho (OIT): no .90 de 1951, sobre a igualdade de remuneração de homens e mulheres trabalhadores por trabalho de igual valor; Recomendação no 165 de 1981 da OIT, sobre Igualdade de oportunidades e de tratamento para homes e mulheres trabalhadoras com encargos de famílias (VERBICARO SOARES, 2012, p. 38). Também se menciona a Convenção no 100 de 1951, sobre a igualdade de remuneração de homens e mulheres por trabalho de igual valor; Convenção no ${ }^{\circ} 111$, de 1958 (TRTSP, 2020), sobre Discriminação em Matéria de Emprego e Ocupação; Convenção $\mathrm{n}^{\mathrm{o}} .156$, de 1981, sobre a igualdade de oportunidades e de tratamento para homens e mulheres trabalhadores com encargo de família.

Segundo a plataforma do Governo brasileiro e suas políticas para a inclusão das mulheres na sociedade brasileira, é importante recordar que desde a década de 2000, com o Plano Nacional de Políticas para as Mulheres (OBSERVATÓRIO DE GÊNERO, 2006) se conteve variadas medidas para esse coletivo majoritário, que envolvia tanto o Governo Federal, como os Estados e os Municípios brasileiros, para conseguir medidas públicas em todo o território, tentando coibir, prevenir a discriminação, combate da violência, auxilio as mulheres e garantir seus direitos.

Nesse sentido, cada setor nacional teria um objetivo: 
Governo federal: Em 2020, através do Ministério da Mulher, da Família e dos Direitos Humanos (GOVERNO FEDERAL, 2020), centraliza todas as informaçóes, elabora planos de trabalho com os Estados e controla suas açôes;

Governos estaduais: definem as programaçóes e as implantaçóes dos planos nos municípios, firma convênios com ONGS e ministérios, e garantem o subsídio necessário para a atuação das prefeituras;

Prefeituras: cada cidade participante do programa garante a utilização dos projetos e presta contas para os governos estaduais. Entre os participantes que trabalharam juntos com o Governo brasileiro estariam: a Casa Civil, o Poder Judiciário, o Ministério Público, a Organização Internacional do Trabalho, por exemplo.

É viável destacar a criação do serviço telefônico do número 180 (GOVERNO FEDERAL, 2020) para as vítimas de risco de maus tratos e violência de gênero, que contam com uma central de atendimentos para as mulheres para todo o país. Nesse aspecto, são inegáveis os esforços para mudanças de paradigmas e na criação de instrumentos que protejam as mulheres de práticas discriminatórias. Mas, também, se deve reconhecer que novas alternativas são necessárias para uma real proteção das mulheres em pleno século XXI.

\section{As mulheres no Ordenamento Jurídico Nacional}

Mudanças na legislaçáo brasileira permitiram, nos últimos tempos, proteçóes específicas para as mulheres, combatendo uma realidade de discriminação histórica. Proteção que objetiva a igualdade de trato entre homens e mulheres. Essa previsão equitativa está regulada pela Constituição Federal de 1988, que preceitua sobre a dignidade humana e proteção ao trabalho feminino.

É importante considerar que esses preceitos de normas de proteção às mulheres buscam modificar o estigma de inferioridade do trabalho da mulher no espaço laboral, permitindo a essas mulheres uma diminuição de obstáculos que impeçam sua integração social. Exemplo dessa proteção está no resguardo da maternidade, em especial no artigo 7o, XVIII da CF/88: licença à gestante, sem prejuizo do emprego e do salário, com a duraçâo de cento e vinte dias (JUSBRASIL, 2020).

$\mathrm{Na}$ mesma Constituição, no artigo $7^{\circ}, \mathrm{XX}$, existe previsão de equiparação entre homens e mulheres, explicitando uma proteção no mercado de trabalho da mulher através de incentivos específicos. $\mathrm{O}$ artigo 7o da Carta Magna, também, proíbe a diferença salarial, no desempenho de mesma função ou critérios de escolha motivados por sexo (JUSBRASIL, 2020).

No ano de 2006 foi criada a Lei Maria da Penha - 11.340/2006, com o objetivo de diminuir os casos de abusos físicos e psicológicos dos homens para as mulheres. De acordo com seu artigo $1^{\circ}$ :

Esta Lei cria mecanismos para coibir e prevenir a violência doméstica e familiar contra a mulher, nos termos do $₫ 8$ o do art. 226 da Constituição Federal, da Convenção sobre a Eliminação de Todas as Formas de Violência contra a Mulher, da Convenção Interamericana para Prevenir, Punir e Erradicar a Violência contra a Mulher e de outros tratados internacionais ratificados pela República Federativa do Brasil; dispóe sobre a criação dos Juizados de Violência Doméstica e Familiar contra a Mulher; e estabelece medidas de assistência e proteção às mulheres em 
situação de violência doméstica e familiar (BRASIL, 2006).

Essa previsão legal teve como fundamento prevenir e combater condutas que vulnerassem as mulheres no âmbito de gênero e familiar, seguindo orientaçôes de Instrumentos Internacionais, como citados previamente nesse estudo, servindo como medida de proteção às mulheres no Brasil.

Dois anos mais tarde, em 2008, no governo do ex-presidente Luis Inácio da Silva, foi aprovada a lei no 11.770 (BRASIL, 2008) que, junto com o Programa Empresa Cidadã, aumentava a licença maternidade de 120 para 180 dias. Possibilidade essa disponibilizadas com o incentivo fiscal para que as empresas que aderissem ao programa do governo: Cria o Programa Empresa Cidadã, destinado à prorrogação da licença-maternidade mediante concessão de incentivo fiscal, e altera a Lei no 8.212, de 24 de julho de 1991.

No ano de 2015, foi sancionada a lei no 13.104 , mais conhecida como lei do feminicídio, cuja ementa leciona:

Altera o art. 121 do Decreto-Lei no 2.848, de 7 de dezembro de 1940 - Código Penal, para prever o feminicídio como circunstância qualificadora do crime de homicídio, e o art. 1o da Lei no 8.072, de 25 de julho de 1990, para incluir o feminicídio no rol dos crimes hediondos (BRASIL, 2015). Na sequência se tem o inciso VI: contra a mulher por razóes da condição de sexo feminino (BRASIL, 2015).

É crucial destacar que esses preceitos constitucionais, junto com a legislação vigente no país possibilitaram uma maior proteção para as mulheres dentro da sociedade brasileira, mas os desafios para a construção efetiva de uma realidade harmônica de respeito a essas pessoas são maiores e necessitam um comprometimento tanto do Estado, como da sociedade para adotar medidas reais para a integração das mulheres em situação de desigualdades e exclusão social.

Em 2019 houve algumas mudanças com relação às políticas públicas destinadas as mulheres como alteraçóes na lei Maria da Penha.

Lei no 13.827, de 13 de maio de 2019 - que autorizou "nas hipóteses que especifica a aplicação de medida protetiva de urgência, pela autoridade judicial ou policial, à mulher em situação de violência doméstica e familiar, ou a seus dependentes, e para determinar o registro da medida protetiva de urgência em banco de dados mantido pelo conselho nacional de justiça” (BRASIL, 2019).

Lei no 13.836, de 4 de junho de 2019 - que tornou "obrigatória a informação sobre a condição de pessoa com deficiência da mulher vítima de agressão doméstica ou familiar" (BRASIL, 2019).

Lei $\mathrm{n}^{\circ}$ 13.871, de 17 de setembro de 2019 - "para dispor sobre a responsabilidade do agressor pelo ressarcimento dos custos relacionados aos serviços de saúde prestados pelo Sistema Único de Saúde (SUS) às vítimas de violência doméstica e familiar e aos dispositivos de segurança por elas utilizados" (BRASIL, 2019).

Lei $n^{\circ}$ 13.880, de 8 de outubro de 2019 - "para prever a apreensão de arma de fogo sob posse de agressor em casos de violência doméstica, na forma em que especifica (BRASIL, 2019).

Lei no 13.882, de 8 de outubro de 2019 - "para garantir a matrícula dos dependentes da mulher vítima de violência doméstica e familiar em instituição de educação básica mais próxima de seu domicílio" (BRASIL, 2019). 
Lei no 13.894, de 29 de outubro de 2019 - que prevê a competência dos juizados de violência doméstica e familiar contra a mulher para a ação de divórcio, separação, anulação de casamento ou dissolução de união estável nos casos de violência (BRASIL, 2019).

Além das Alterações na Lei Maria da Penha tiveram outros avanços legais, tais como a lei no 13.931, de dezembro de 2019 que 区torna compulsória a notificação de casos de suspeita de violência contra a mulher pelos serviços de saúde às autoridades policiais】 (BRASIL, 2019).

É verdade que em se tratando de avanços legislativos tivemos seriam modificaçóes que geraram acalorado debate acerca de suas eficácias, mas apesar de tantas mudanças o Brasil continua tendo um número alarmante quando se trata de violência e preconceito contra a mulher por pura questáo de gênero. Cumpre dizer que o Brasil ainda tem um grande caminho a percorrer para chegar próximo ao ideal de igualdade táo almejado, mas que pelo menos os passos iniciais já foram dados.

\section{As mulheres no contexto roraimense}

O cenário do Estado de Roraima, apesar das paisagens naturais e empreendedorismo forte por ser considerado um estado relativamente "jovem", traz à vista a necessidade de um olhar mais atencioso perante as autoridades públicas, pois se trata de uma área de fronteira seca onde a conexão entre países semelhantes como Brasil, Guiana e Venezuela perpassa costumes distintos, legislaçóes e estruturas governamentais heterogêneas.

As áreas de Roraima e Bolívar, bem como os dois municípios fronteiriços, Pacaraima e Santa Elena de Uairém, possuem elementares sociais, econômicas e geográficas peculiares. Por estarem inseridos em um campo de distanciamento dos centros de poder, somados à falta de conhecimento sobre direitos, aliados à extrema pobreza, fatores que somados, convertem-se em uma realidade deplorável para aqueles cidadãos mais vulneráveis que necessitam da proteção estatal.

O território ligado pela BR-174, principal rodovia que une o caribe venezuelano ao Brasil (OLIVEIRA, 2016, p. 25), interligando Manaus, os municípios de Roraima e a Venezuela, é tida por diversos estudos como principal rota internacional de tráfico de drogas, prostituição, exploração sexual, mineração ilícita, contrabando entre outras mazelas sociais.

Os países fronteiriços em questão, (Brasil e Venezuela) possuem altos índices de violência praticada em razão do gênero, sendo que este cenário gera para as crianças, adolescentes, mulheres indígenas e migrantes, uma situação de fragilidade, tornando-as mais vulneráveis a este tipo de agressão a partir do contexto da regiáo.

Além disso, o interesse pelas cidades venezuelanas e brasileiras, com vocaçáo garimpeira, reafirma a tendência na região norte do Brasil para a rede de agenciamento de projetos de desenvolvimento e infraestrutura. Desse modo, o crescente mercado da prostituição e o tráfico de mulheres se desenvolvem acompanhando esta mesma lógica, isto é, seguindo fluxos migratórios, aumentando e diminuindo de acordo com o ritmo da movimentação das obras e da garimpagem. (OLIVEIRA, 2008).

Na obra "Tráfico de Mulheres na Amazônia" se ressalta que "o fato social da mercantilização do corpo está diretamente ligado à condição social e étnico-racial", ou seja, a ocorrência de mulheres migrantes, indígenas e brasileiras estarem mais suscetíveis ao tráfico internacional e 
à violência, é fruto das perversas hierarquias de gênero, raça e classe, onde o crime organizado encontra espaço propício para a ação (TORRES; OLIVEIRA, 2012, p. 37).

A prostituição que se instala em áreas de garimpo em Roraima, segundo pesquisas, alcança também as aldeias indígenas que habitam as margens da BR-174, como exemplo a Reserva São Marcos, Sorocaima II e regióes próximas ao Município de Pacaraima, sendo que esta rede é voltada quase que exclusivamente, para atender a garimpeiros da localidade. Assim, a presença de turistas à procura da atividade é encarada por proprietários de estabelecimentos dedicados à prostituição com muita desconfiança, demonstrando um público específico (clientela) direcionado a esta atividade.

Em pesquisa realizada no âmbito nacional, com vistas a compreender melhor o fenômeno da prostituição e traçar um perfil da exploração e do tráfico no Brasil, denominada de PESTRAF - Pesquisa sobre o Tráfico de Mulheres, Crianças e Adolescentes para fins de Exploração Sexual Comercial no Brasil, Roraima é apontada como rota internacional do tráfico via BR-174, sendo que o itinerário de Manaus para Boa Vista e depois para Pacaraima na fronteira com a Venezuela visa atingir países da Europa como Espanha, Holanda e Portugal (PESTRAF, 2002).

É imperioso considerar como elemento fomentador de práticas de violência sexual e tráfico, o intenso movimento migratório Venezuela-Brasil, o qual resulta em um crescimento populacional desordenado. Assim, a "rota" é viabilizada pela inexistência e fragilidade de fiscalização por parte da polícia, que não impóem grandes dificuldades para os traficantes e aliciadores, os quais buscam transpor a fronteira norte do país para alcançar especialmente, as áreas de garimpo da Venezuela e da Guiana Inglesa.

\section{As medidas protetivas}

Em 2012, foi promovida a criação do Comitê Binacional Fronteiriço entre Brasil e Venezuela para Enfrentamento à Violência Contra Mulheres (XAUD, 2017), uma ação conjunta entre diferentes instituiçóes públicas dos dois países, buscando promover a cooperação e a melhora no acolhimento à mulher vítima de qualquer tipo de agressão e discriminação em razão do gênero, independentemente de sua nacionalidade.

Neste intuito, o Comitê Binacional teve a sua criação oficializada em 2012, mas, ao final do ano seguinte houve a suspensão não declarada dos trabalhos, encontros e discussóes, o que trouxe prejuízos à evolução dos diálogos que estavam ocorrendo em todos os órgãos e instituiçôes pertencentes à rede de enfrentamento, fato extremamente danoso à política idealizada.

Dentro dos eixos do Programa do Governo Federal "Mulher: Viver Sem Violência!" Previu-se a implantação e manutenção de Centros de Atendimento às Mulheres nos Municípios de Pacaraima (Brasil) e Gran Sabana, na Venezuela (GOVERNO FEDERAL, 2013), consideradas principais linhas de ação das políticas públicas de cooperação binacional, com o objetivo primordial acolher e atender à mulher migrante, indígena, ribeirinha e trabalhadora rural.

A rede de enfrentamento fronteiriça foi constituída, aparelhada, só que de forma irregular, possuindo estrutura física e de pessoal, conectada para o trabalho em conjunto, mas, ao contrário do que se idealizou, sem uma articulação de forma a executar o trabalho efetivamente binacional, existindo apenas em razão da oferta de serviços através dos Centros em Pacaraima e Santa Helena de Uairém. 
A crise político-econômico-social enfrentada fortemente pela Venezuela contribuiu em grande parte para a paralisaçáo dos trabalhos do Comitê Brasil e Venezuela, e a rede de enfrentamento binacional segue atuando sem reconhecer-se definitivamente enquanto rede. Lastima-se que o acesso das mulheres mais vulneráveis ao sistema de justiça é incipiente, sem acesso à devida assistência jurídica e social, idealizada nas legislaçôes protetivas.

\section{A mulher indígena roraimense}

Com relação à especificidade dos povos indígenas em Roraima, é imprescindível considerar a diversidade étnico-cultural desses grupos que aqui se apresentam, originando diversas famílias linguísticas através da ocupação massiva em grande parcela do território abrangido pelas vastas terras demarcadas, bem como parques nacionais.

Há alguns anos, muitas reuniôes na formação das primeiras organizaçôes indígenas aconteciam com a presença e participação das mulheres de maneira bastante limitada. Suas atividades resumiam-se em limpeza, preparar e servir os alimentos, e estas não exerciam nenhuma liderança política ou cargo de destaque. Mesmo após a criação do Conselho Indígena de Roraima (CIR), assembleias passaram a acontecer em diversas comunidades, mas o número de mulheres era reduzido e estas não possuíam direito a voz e voto (SANTOS, 2019, p. 38).

Durante muito tempo, o meio de representação da aldeia tem sido através de tuxauas do sexo masculino. De acordo com o livro: Movimentos indígenas e conflitos territoriais no estado de Roraima, as lideranças indígenas são escolhidas para representar as populaçóes das malocas ou aldeamentos, considerados porta vozes nas assembleias e reuniōes. Desse modo, a situação das lideranças historicamente é tida como função de exercer uma espécie de mediação polifônica, que habilita o campo das relaçóes entre sociedades (REPETTO, 2008, p. 117).

Com a implantação do "Projeto de Corte e Costura" em 1996, uma associação entre a Diocese de Roraima e os conselhos regionais indígenas, foi promovida a primeira manifestação coletiva de mulheres indígenas. Deu-se com a compra de máquinas de costura e capacitaçáo das mulheres na produção de peças de vestuário. Posteriormente, o movimento consolidou-se e recebeu apoio de outras organizaçóes como o Núcleo de Mulheres de Roraima (NUMUR), o qual atua no enfrentamento à violência de gênero em Roraima (FREITAS; TORRES, 2017).

Destarte, alguns autores defendem a possibilidade de conciliação entre o feminismo e o multiculturalismo, na condiçáo de que sejam relativizados, ao analisarmos que as mulheres indígenas roraimenses podem ser representantes e defensoras dos direitos de seus grupos, alcançando cargos de liderança (LIMA et tal., 2017, p. 96).

Dado o exposto, a história do movimento feminista indígena é algo recente na história roraimense, através de suas formas organizativas poderâo sair gradativamente da invisibilidade e silenciamento que historicamente marcaram a sua presença nas assembleias e lideranças comunitárias. Há muito ainda a se caminhar com auxílio de organizaçóes e o poder público, promovendo medidas e açôes protetivas às mulheres indígenas em Roraima.

\section{Consideraçóes finais}

A história revelou que através da organização de grupos sociais, as mulheres paulatinamente 
foram logrando emancipação social e acesso a restritos direitos. Em meios às greves, movimentos sociais, regulaçôes legislativas para a proteção feminina foram sendo construído um ambiente para a incorporação das mulheres e na luta pela igualdade com seus companheiros homens.

Em Roraima, a especificidade migrante e indígena é marca no estado, e devido às condiçôes sociais e políticas de fronteiriças que existem, a violência de gênero é índice intrínseco na regiāo. Medidas de proteção às mulheres foram adotadas, porém a rede de enfrentamento aos crimes ainda é microscópica frente à problemática que envolve múltiplos fatores enraizados.

Ademais, ao analisar o 'ser mulher indígena em Roraima' estamos diante de uma dupla expressão desafiadora. Ao mesmo tempo em que a indígena roraimense demonstra anseio de equiparar-se ao sexo masculino na representação do povo e na luta por direitos, não tem o desígnio de deixar os costumes e os modos próprios de sua cultura, assim não pretende igualarse a mulher não indígena para gozar das mesmas garantias que são disputadas por estas. Desse modo, evidencia-se a possibilidade de harmonia entre o multiculturalismo e o feminismo na luta pela igualdade de gênero.

Para lograr esse objetivo de erradicação do preconceito e discriminação, o presente estudo aponta com alternativa o desenvolvimento de políticas educativas voltadas para a sensibilização social, em especial em questôes sobre a emancipação das mulheres no ambiente laboral e rompendo estigmas de condenaram essas mulheres ao cuidado familiar e do âmbito familiar restritamente.

\section{Referências}

BRASIL. Lei no 11.340, de 7 de agosto de 2006. Disponível em: <http://www.planalto.gov. br/ccivil_03/_Ato2004-2006/2006/Lei/L11340.htm>. Acesso em 29 dez. 2020.

BRASIL. Lei no 11.770, de 9 de setembro de 2008. Disponível em: <http://www.planalto. gov.br/ccivil_03/_Ato2007-2010/2008/Lei/L11770.htm>. Acesso em 29 dez. 2020.

BRASIL. Lei no 13.104, de 9 de março de 2015. Disponível em: <http://www.planalto.gov. br/ccivil_03/_Ato2015-2018/2015/Lei/L13104.htm>. Acesso em 29 dez. 2020.

BRASIL. Lei no 13.827, de 13 de maio de 2019. Disponível em: <http://www.planalto.gov. br/ccivil_03/_Ato2019-2022/2019/Lei/L13827.htm>. Acesso em 29 dez. 2020.

BRASIL. Lei no 13.836, de 4 de junho de 2019. Disponível em: < http://www.planalto.gov. br/ccivil_03/_ato2019-2022/2019/lei/L13836.htm>. Acesso em 29 dez. 2020.

BRASIL. Lei no 13.871, de 17 de setembro de 2019. Disponível em: <http:/www.planalto. gov.br/ccivil_03/_ato2019-2022/2019/lei/L13871.htm>. Acesso em 29 dez. 2020.

BRASIL. Lei no 13.880, de 8 de outubro de 2019. Disponível em: <http://www.planalto.gov. br/ccivil_03/_ato2019-2022/2019/lei/L13880.htm> . Acesso em 29 dez. 2020.

BRASIL. Lei no 13.882, de 8 de outubro de 2019. Disponível em: <http://www.planalto.gov. br/ccivil_03/_ato2019-2022/2019/lei/L13882.htm>. Acesso em 29 dez. 2020.

BRASIL. Lei no 13.894, de 29 de outubro de 2019. Disponível em: <http://www.planalto. gov.br/ccivil_03/_Ato2019-2022/2019/Lei/L13894.htm>. Acesso em 29 dez. 2020. 
BRASIL. Lei no 13.931, de dezembro de 2019. Disponível em: <http://www.planalto.gov.br/ ccivil_03/_ato2019-2022/2019/lei/L13931.htm>. Acesso em 29 dez. 2020.

BUSTOS, Ma Ángeles. La mujer ante el siglo XXI: una perspectiva desde el ordenamiento jurídico-administrativo. Badajoz, Espanha: @becedario, 2006.

CARDOSO, Adriano; ZIMMERMANN, Tânia. Reflexóes sobre gênero e homossexualidade em grafitos escolares. In.: Humanidades \& Tecnologia em Revista (FINOM) - ISSN: 1809-1628. Ano XIV, vol. 20, p. 142-158, Jan/jul, 2020.

DIAS, Maria Berenice. Homoafetividade e direitos LGBTI. 7a Edição revisada, atualizada e ampliada. São Paulo, Brasil: Revista dos Tribunais, 2016.

FREITAS; TORRES. $\mathbf{O}$ movimento de mulheres indígenas em roraima: o protagonismo feminismo na luta pelos seus direitos. In.: Seminário Internacional Fazendo Gênero $11 \&$ 13th Women’s Worlds Congress (Anais Eletrônicos), Florianópolis, Brasil, 2017.

GALVÁN, Clara. Principio de igualdad y transversalidad de género. Madri, Espanha, 2010.

GOVERNO FEDERAL. Denunciar e buscar ajuda a vítimas de violência contra mulheres (Ligue 180). Disponível em: <https://www.gov.br/pt-br/servicos/denunciar-e-buscarajuda-a-vitimas-de-violencia-contra-mulheres\#:- :text=No\%20Brasil\%3A\%20180.,o\%20 n\%C3\%BAmero\%2061\%203799\%2D0180>. Acesso em 29 dez. 2020.

GOVERNO FEDERAL. 25/10 - Roraima adere ao 'Mulher, Viver sem Violência', na $3^{\text {a }}$ feira, para ampliar rede de serviços especializados. Disponível em: $<\mathrm{https}$ :/www.gov. $\mathrm{br} / \mathrm{mdh} / \mathrm{pt}$-br/navegue-por-temas/politicas-para-mulheres/arquivo/area-imprensa/ultimas_ noticias/2013/10/25-10-roraima-adere-ao-2018mulher-viver-sem-violencia2019-na-3a-feirapara-ampliar-rede-de-servicos-especializados>. Acesso em 29 dez. 2020.

GOVERNO FEDERAL. Ministério da Mulher, da Família e dos Direitos Humanos. Disponível em: <https://www.gov.br/mdh/pt-br>. Acesso em 30 dez. 2020.

JUSBRASIL. Art. 7, inc. XVIII da Constituiçáo Federal de 88. Disponível em: <https:// www.jusbrasil.com.br/topicos/10726402/inciso-xviii-do-artigo-7-da-constituicao-federalde-1988>. Acesso em 30 dez. 2020.

JUSBRASIL. Art. 7, inc. XX da Constituiçáo Federal de 88. Disponível em: <https://www. jusbrasil.com.br/topicos/10726330/inciso-xx-do-artigo-7-da-constituicao-federal-de-1988>. Acesso em 30 dez. 2020.

JUSBRASIL. Art. 7, inc. XXX da Constituiçáo Federal de 88. Disponível em: <https://www. jusbrasil.com.br/topicos/10725856/inciso-xxx-do-artigo-7-da-constituicao-federal-de-1988>. Acesso em 30 dez. 2020.

LALAGUNA, Paloma; SALAZAR, Ana. La igualdad de género en el contexto internacional. In.: CONDE, Enrique Álvarez y otros. Estudios Interdisciplinares sobre Igualdad. Madri, Espanha: Iustel. Instituto de Derecho Público, 2011.

LIMA, Nathalia; ANDRADE, Denise; MODERNELL, Barbara; SILVA, Solange. A experiência da organização das mulheres indígenas de roraima: uma reflexáo sobre multiculturalismo a partir das contribuiçóes de susan okin. Interfaces Científicas - Humanas 
e Sociais. Aracaju, Brasil, Outubro, 2017.

OBSERVATÓRIO DE GÊNERO. Plano Nacional de Políticas para as mulheres.

Disponível em: <http://www.observatoriodegenero.gov.br/eixo/politicas-publicas/pnpm/ipnpm/I\%20PNPM_versao\%20compacta.pdf>. Acesso em 30 dez. 2020.

OLIVEIRA, Thiago. A construçáo da BR-174 (1967-1977) e os Waimiri-Atroari.

Monografia apresentada como requisito para obtenção do título em Licenciatura e Bacharelado em História pela Universidade Federal de Roraima - UFRR. Boa Vista, Brasil, 2016, 74 f.

OLIVEIRA, Rafael. Um olhar sobre as redes de prostituiçáo e tráfico de mulheres na fronteira brasil-venezuela a partir das rodovias br-174 e troncal 10. Universidad de Barcelona, 2008. Disponível em: <http://www.ub.es/geocrit/-xcol/222.htm>. Acesso em 30 dez. 2020.

PESTRAF. Pesquisa sobre tráfico de mulheres, crianças e adolescentes para fins de exploração sexual comercial - pestraf: relatório nacional. Brasília, Brasil: CECRIA, 2002.

PROBST, Elisiana. A evoluçáo da mulher no mercado de trabalho. Disponível em: <http:// www.icpg.com.br/artigos/rev02-05.pdf>. Acesso em 30 dez. 2020.

REPETTO, Maxim. Movimentos indígenas e conflitos territoriais no estado de roraima. UFRR. Boa Vista, Brasil, 2008.

REVISTA PARANAENSE DE DESENVOLVIMENTO. Brasileiros e brasileiras na Espanha: mercado de trabalho, seguridade social e desemprego. Curitiba, Brasil. No.121, pp. 65-89, jul. / dez, 2011.

RODRIGUES, Maria de Lourdes; SELEM, Maria Célia. Conselhos dos Direitos no Brasil. Curitiba, Brasil: Ágere Cooperação em Advocacy; Secretaria Especial dos Direitos Humanos/ PR. Disponível em: <http://www.dhnet.org.br/dados/cursos/dh/cc/a_pdf/modulo3-tema6aula4.pdf >. Acesso em 30 dez. 2020.

SANTOS, Solange. Mulheres invisíveis fazem história 1980-2019. UFRR. Boa Vista, Brasil, 2019.

SENADO. Carta de Direitos Humanos completa 70 anos em momento de incertezas. Disponível em: <https://www12.senado.leg.br/noticias/infomaterias/2018/12/70-anos-dadeclaracao-universal-dos-direitos-humanos>. Acesso em 30 dez. 2020.

TORRES, Iraildes; OLIVEIRA, Márcia. Tráfico de mulheres na amazônia. Florianópolis, Brasil: Editora Mulheres, 2012.

TRTSP. Convenção n. 111. Disponível em: <http://www.trtsp.jus.br/geral/tribunal2/LEGIS/ CLT/OIT/OIT_111.html>. Acesso em 30 dez. 2020.

VALLADARES, Lola. Derechos sexuales. Disponível em: <http://catedra-laicidad.unam.mx/ sites/default/files/Derechossexuales.pdf>. Acesso em 30 dez. 2020.

VERBICARO SOARES, Douglas. A revelação da orientação homossexual prevista emaspectos familiares na sociedade brasileira: a imposição de ideais heteronormativos e discriminatórios para uma minoria que ultrapassa o condicionamento do rosa ou azul. In.: Revista Di@logus. Cruz Alta, Brasil, v. 8, no 2, p. 72-97, 2019. 
VERBICARO SOARES, Douglas. Discriminação homosexual na ideología cristã. Revista Missioneira. Santo Ângelo, Brasil, v. 21, no 1, p. 10-35, 2019.

VERBICARO SOARES, Douglas. Las mujeres y las personas homosexuales en las Fuerzas Armadas. Especial referencia a las FFAA Brasileńas. Trabajo fin de Máster. Programa Estudios Interdisciplinares de Género y Políticas de Igualdade. Faculdade de Direito. Universidade de Salamanca - USAL, Salamanca, España, 2012. 146 p.

VERBICARO SOARES, Douglas. O estudo da orientação homossexual pensado dos Direitos Humanos e na sociedade brasileira. Revista BAGOAS. Natal, Brasil, v. 20, p. 121-163, 2019.

VERBICARO SOARES, Douglas; DEMÉTRIO, Rafaela; MORAIS, Rafael. O que ocorreu após o episódio de Laci de Araújo em 2008? A homossexualidade discutida nas Forças Armadas do Brasil. Revista Direito e Justiça: reflexões sóciojurídicas. Santo Ângelo, Brasil, v. 20, no 37, p. 85-103, 2020.

VERBICARO SOARES, Douglas; BEDONI, Marcelo; MONTCHO, Sedjro. Controvérsias jurídicas no Brasil sobre a doação de sangue por homossexuais e a educação como principal alternativa contra o preconceito. Revista Di@logus, v. 9 (1), p. 43-68, 2020.

VIEIRA, Yvonne. Identidade do homem na sociedade patriarcal. In.: Macho masculino homem. São Paulo, Brasil: LPM Edtores, 1986.

XAUD, Jeane. A cooperaçáo binacional entre o brasil e venezuela relativa à rede de enfrentamento da violência praticada contra mulheres. In.: Seminário Internacional Fazendo Gênero 11 \& 13th Women's Worlds Congress (Anais Eletrônicos). Florianópolis, 2017.

WOLLSTONECRAFT, Mary. Vindicación de los derechos de la mujer. Madri. Espanha, 1977. 